\title{
Modified Push-Off Testing of an Inclined Shear Plane in Reinforced Concrete Strengthened with CFRP Fabric
}

\section{Citation:}

R.M. FOSTER, C.T. MORLEY and J.M. LEES (2015) Modified Push-Off Testing of an Inclined Shear Plane in Reinforced Concrete Strengthened with CFRP Fabric, IN: ASCE Journal of Composites for Construction, issue tbc

Additional Information:

- Available online as of: 30 September 2015

- DOI: 10.1061/(ASCE)CC.1943-5614.0000623

- Additional data related to this publication is available at the University of Cambridge's institutional data repository: https://www.repository.cam.ac.uk/handle/1810/249023.

Version:

Accepted for publication 


\title{
Modified Push-Off Testing of an Inclined Shear Plane in Reinforced Concrete Strengthened with CFRP Fabric
}

\author{
Robert M. Foster ${ }^{1}$, Chris T. Morley ${ }^{2}$ and Janet M. Lees ${ }^{3}$
}

\begin{abstract}
This study reports the findings of an experimental investigation into the behaviour of an inclined shear plane in reinforced concrete, such as a diagonal crack in the web of a beam, strengthened with externally bonded Carbon Fibre Reinforced Polymer (CFRP) fabric. A modified push-off test of novel geometry was developed for this study. This test generates a diagonal failure plane subject to combined shear and tension. Both unwrapped and wrapped tests were conducted, allowing the load sharing and load displacement behaviour of the reinforced concrete, and the reinforced concrete with externally bonded CFRP fabric, to be investigated. Fully wrapped and U-wrapped CFRP fabric configurations were tested. Results indicate that for the arrangement tested, concrete, steel and CFRP contributions to resistance are not independent, and that effective anchorage lengths given in the UK and US guidance for U-wrapped CFRP may not be adequate in some cases.
\end{abstract}

\section{INTRODUCTION}

The cost of assessing and strengthening deficient bridges structures has been estimated as being in excess of $£ 4$ billion for the UK (Middleton 2004) and $\$ 140$ billion for the US (American Association of State Highway Transportation Officials 2008). Deficiencies in the strength of reinforced concrete infrastructure can arise due to a variety of factors including deterioration,

\footnotetext{
${ }^{1} \mathrm{PhD}$ student, University of Cambridge, UK. Corresponding author, email: rmf41@cam.ac.uk

${ }^{2}$ Former Senior Lecturer, Department of Engineering, University of Cambridge, UK

${ }^{3}$ Reader in Civil Engineering, Department of Engineering, University of Cambridge, UK
} 
construction defects, accidental damage, changes in understanding and failure to design for future loading. The demolition and replacement of such structures can involve large capital expenditure; environmental impacts; lengthy interruptions to service; over-burdening of nearby infrastructure; and local opposition to construction works. Approaches to strengthening existing concrete structures insitu through retrofit are therefore of considerable interest to infrastructure owners seeking to extend a structure's useful life. Of increasing interest as materials for use in concrete strengthening applications are Fibre Reinforced Polymers (FRP) and in particular Carbon Fibre Reinforced Polymers (CFRP) due to their favourable strength to weight ratios and resistance to various forms of corrosion.

One method for the shear strengthening of existing slab-on-beam structures is the use of externally bonded FRP fabric to U-wrap the down-stand portion of the shear span. The Uwrapping approach typically involves a manual layup procedure whereby the FRP fabric is externally bonded to the prepared concrete surface with an epoxy resin. This avoids the need to break out areas of concrete or drill into the section with the associated risks of exposing or damaging existing reinforcement.

Current guidance for shear strengthening with externally bonded FRP fabrics includes: UK Technical Report No. 55 (TR55) (Concrete Society 2012) based on the work of Denton et al (2004), American Concrete Institute (ACI) 440.2R-08 (ACI 2008) based on the work of Khalifa et al (1998), and International Federation for Structural Concrete (fib) Bulletin 14 (fib 2001) based on the work of Triantafillou \& Antonopoulos (2000). While the three approaches differ, principally in respect to the determination of the strains in the FRP, all can be characterised as methods of 'superposition'. That is to say that, for the purpose of adopting a pure truss analogy to describe the underlying shear resisting system, it is assumed for TR55 and fib Bulletin 14, 
further to Eurocode 2 that:

$$
V_{u}=\min \left(V_{s}+V_{f r p}, V_{\max }\right)
$$

while ACI 440.2R-08 includes an additional empirically derived component $V_{c}$ :

$$
V_{u}=\min \left(V_{c}+V_{s}+V_{f r p}, V_{\max }\right)
$$

where $V_{u}$ is the ultimate shear resistance of the element; $V_{c}, V_{s}$, and $V_{f r p}$ are the shear resisting contributions of the concrete, steel and FRP respectively; and $V_{\max }$ is a limit preventing failure by crushing of a concrete strut. Superposition assumes that the component resistance systems are mutually independent and co-existent; implying that the concrete and transverse steel resisting systems are unaffected by the addition of the FRP and the contribution of the FRP system is unaffected by the internal transverse steel reinforcement provision. The assumption of mutual independence is drawn into question by recent experimental and analytical results. While the evidence with respect to the effect of FRP strengthening on the yielding of transverse steel reinforcement is mixed (Chen et al. 2012; Mofidi et al. 2014), there are clear indications that the enhancement due to FRP strengthening decreases with increasing provision of transverse reinforcement (Mofidi et al. 2014; Bousselham et al. 2006; Belarbi et al. 2012).

Analysis by Lima and Barros (2011) of a database of more than 250, predominantly rectangular, FRP strengthened beam tests concluded that for a range of externally bonded FRP strengthening 
configurations, the studied prediction methods were inadequately robust for the purposes of design. Dirar et al. (2012) found that the formulae set out in TR55 $2^{\text {nd }}$ Ed. (Concrete Society 2004), along with those set out in ACI 440.2R-08 and fib Bulletin 14, over predicted the Uwrapped FRP contribution when compared to some experimental T-beam test results. These findings raise important questions as to the adequacy and conservatism of current guidance. The latest revision (2012) of TR55 amends a number of factors to improve agreement with experimental data but the underlying superposition model is preserved.

In the current work, an experimental investigation was carried out as part of a broad study into the behaviour of reinforced concrete beams strengthened in shear with externally bonded carbon fibre reinforced polymer (CFRP) fabric. In order to gain insight into the effect of diagonal cracking through an element of reinforced concrete with and without CFRP, a modified push-off test of novel geometry was developed. The modified push-off experiments provide a better fundamental understanding of the behaviour of the concrete, steel and FRP before, and after, crack formation and this helps to inform whether methods of superposition are valid. Although the study primarily focused on load-sharing in CFRP strengthened concrete, in addition to the conclusions of this investigation, the underlying conceptual development and embodiment of the modified push-off testing approach itself represents a contribution with wide applicability to reinforced concrete research.

\section{BASIS FOR INVESTIGATION}

There are two critical areas to explore in furthering our understanding of the local load sharing and behaviour of the concrete, steel and FRP under conditions pertaining to those found in the web of a strengthened beam. The first is the effect of tensile normal stresses along an inclined shear plane, such as a diagonal crack in the web of a beam. The second is the effect of the 
variation in the FRP anchorage length due to the inclination of the shear plane, as occurs above a diagonal crack in the web of a U-wrapped beam. These effects are highlighted schematically in Figure 1. The modified push-off testing programme adopted in the study was not intended to simulate full beam behaviour, but rather to provide a means of considering the behaviour of a small length of inclined crack crossed by internal reinforcement and externally bonded CFRP, and subject to a combination of shear and tension.

\section{Effect of normal stresses on shear transfer}

The transfer of shear across an interface has been the subject of much research. Experimental investigations, notably by Hofbeck et al. (1969), Mattock \& Hawkins (1972) and Walraven \& Reinhardt (1981), have typically involved the use of 'push-off' tests (Figure 2a). Conventional push-off tests are designed to elicit pure shear across an interface by forming a failure plane concentric with, and parallel to, an applied load, $F$. Roughness of the interface due to the presence of aggregate and other deviations means that, for slip of the two halves of the specimen to occur along the interface, there must be sufficient crack dilation for the opposing faces either to override (Birkeland \& Birkeland 1966), or else for the formation and rotation of diagonal 'struts' in the concrete to occur (Hofbeck et al 1969). Dilation strains any reinforcement crossing the interface and commensurate restraint forces are developed in turn. The effects of a variety of parameters have been explored in initially cracked push-off specimens and to a lesser extent in initially un-cracked specimens, by various investigators. These parameters have included: concrete strength (Hofbeck et al. 1969; Mattock \& Hawkins 1972; Walraven \& Reinhardt 1981); aggregate type (Mattock et al. 1976), size and grading (Walraven \& Reinhardt 1981); steel reinforcement size, proportion and yield strength (Hofbeck et al. 1969; Mattock \& Hawkins 1972; Walraven \& Reinhardt 1981; Harries et al. 2012); inclination of internal steel 
reinforcement (Mattock 1974); effect of internal and unbonded external steel restraint (Walraven \& Reinhardt 1981); effect of bonded internal and external FRP restraint (Grusova et al. 2013); and the influence of compressive normal forces (Mattock \& Hawkins 1972) and tensile normal forces and moments (Mattock et al. 1975) . Of particular interest to the present investigation is the work of Mattock \& Hawkins (1972) on the influence of normal forces across a shear plane.

Mattock \& Hawkins modified the conventional specimen geometry to produce a "modified pushoff specimen" (Figure $2 \mathrm{~b}$ ) that induced a diagonal failure plane (at $+v e$ angles $\theta$ varying from $0^{\circ}$ to $75^{\circ}$ ) concentric with, but inclined to, the applied load. This arrangement generated a failure plane subject to a combination of shear, $F \cos \theta$, and a $\operatorname{compression,~} F \sin \theta$. In all cases the reinforcement was arranged perpendicular to the failure plane. Also investigated were a series of conventional push-off tests with embedded bars perpendicular to the interface, allowing tension to be generated across the failure plane (Figure 2c). These tests were carried out with a fixed tension applied and then subject to increasing shear load.

Figure 3 summarises normalised push-off test results for uncracked specimens of the type shown in Figure 2a) conventional, b) modified $+v e \theta$, and c) conventional with tension, carried out by Mattock \& Hawkins (1972), and Mattock et al. (1975). $v_{u}$ is the nominal average shear stress on the shear plane, $f_{c}$ is the concrete compressive cylinder strength, $\sigma_{\mathrm{s}}$ is the stress normal to the shear plane due to the restraining effect of the internal steel reinforcement and $\sigma_{\mathrm{n}}$ is the externally applied stress (compression $+v e$ ) normal to the shear plane. The modified specimens with $+\mathrm{ve} \theta$ and the conventional specimens with tension show relatively good agreement with the conventional results, indicating that the superposition of moderate normal stresses with the passive restraint stresses due to the reinforcement is not unreasonable. However, in the region in which a net tension is present across the shear plane, there is an absence of experimental results. 
This is significant because, although the contribution of concrete tensile strength is typically neglected in strength design, the pattern of results indicates potential non-zero shear strength in this region.

In order to investigate the case of a net tension across the shear plane, a further modification to the geometry of the push-off specimen was developed for this study. These specimens form a failure plane at a $-v e$ angle $\theta$ (Figure 2d), thereby generating an interface subject to a combination of shear, $F \cos \theta$, and tensile normal force, $F \sin \theta$ (Figure 2d). For the purposes of this initial investigation, specimens forming a failure plane at $\theta=-45^{\circ}$ were tested. The internal steel reinforcement was oriented parallel to the applied loading and thus at $45^{\circ}$ to the failure plane (Figure 4). This arrangement is analogous to that found at a diagonal crack in the web of a beam (c.f. Figure 1, Figure 2d). Further advantages of this design are that the internal steel reinforcement can be varied, bonded FRP can be applied, and a variety of anchorage conditions can be considered.

\section{Effect of variation of FRP anchorage length}

The inclination of a diagonal crack in a reinforced concrete beam means that the length available for anchorage of an externally bonded U-wrap varies along the crack length (Figure 1). The maximum strength realisable for a bonded FRP is, in general, significantly less than the full tensile strength of the FRP itself. The concept of a maximum effective anchorage length, $L_{e}$, is common to ACI440.2R-08, TR55 and fib 14 (although fib 14 does not explicitly account for $L_{e}$ with respect to shear strengthening, c.f. fib 14 section 5.1.2.3). $L_{e}$ is taken to be the length over which all of the bond force is transferred and thus represents the bonded length beyond which no incremental increase in FRP strength can be realised. Forces greater than that transferable over $L_{e}$ can be thought of as initiating a propagating de-bonding zone or 'wave-front' that leads to 
progressive debonding failure. The expressions for $L_{e}$ vary very significantly between the ACI code, and the fib 14 and TR55 guidance; positing different relationships between $L_{e}$ and FRP stiffness (Table 1), with FRP stiffness determined as a function of $n_{F R P}, t_{F R P}$ and $E_{F R P}$, the number of layers, thickness per layer and Young's modulus of the FRP respectively, according to ACI440.2R-08; and as a function of $T_{F R P}, E_{F R P}$ and $f_{c t m}$, where $T_{F R P}$ is the total FRP thickness and $f_{c t m}$ is the mean concrete tensile strength, according to TR55. This difference is likely due to the differing experimental data to which the expressions for $L_{e}$ have been fit, with the ACI values based on the work of Khalifa et al. (1998) and the TR55 values based on the testing of Neubauer \& Rostasy (1997). For the CFRP used in this investigation, effective anchorage lengths determined by TR55 are similar or more onerous than the ACI values (Table 1). Henceforth, $L_{e}$ has therefore been calculated as $L_{t, \max }$ in accordance with TR55 with all explicit safety factors set equal to 1 .

An important consideration in relation to anchorage length at a discrete crack in initially uncracked concrete is that the high strains in the bonded FRP local to the crack must be relieved by some combination of fracture, debonding and bond slip. While methods such as partial interaction theory have been shown to permit detailed consideration of these effects (Haskett et al., 2009), the design codes do not appear to consider this crack bridging explicitly. The provision of an effective anchorage length suggested by the code expressions (Table 1) in experimental test specimens will make it possible to ascertain whether this length is sufficient to accommodate both the length required for the relief of the high strains at the newly opened crack and the bonded length required to transfer the bond stresses to the concrete.

\section{EXPERIMENTAL INVESTIGATION}

\section{Materials}


A test series of nine reinforced concrete push-off specimens were fabricated for use in this study.

For the end blocks, substantial deformed high yield internal reinforcement (Figure 4) was provided to carry forces through the two halves of the specimen and to ensure failure through the plane under investigation. This reinforcement does not cross the $250 \times 200 \mathrm{~mm}$ shear plane. The internal steel test reinforcement crossing the shear plane was $6 \mathrm{~mm}$ diameter round mild steel bar, nominally S275, in the form of conventionally detailed full stirrups. The reduced bond associated with smooth bar in comparison to deformed bar is thought to provide a suitable adverse case for the sharing of load with the external strengthening and for minimising local crack bridging effects that might serve to impede debonding of the FRP. Round mild steel has also been historically used in shear stirrups in many older structures that are thought to be typical candidates for strengthening. The stirrup reinforcement had a $0.2 \%$ offset yield strength, $f_{y}$, of $545 \mathrm{MPa}$ and an ultimate strength, $f_{u}$, of $630 \mathrm{MPa}$.

A unidirectional woven carbon fibre fabric was used in conjunction with a two part epoxy resin adhesive to produce the externally bonded CFRP composite sheets. The composite CFRP material had a tensile strength of $350 \mathrm{MPa}$, an elastic modulus of $28000 \mathrm{MPa}$ and an ultimate strain of $1.2 \%$ according to the manufacturer's data sheet (Sika Ltd. 2006). Nominal thickness per layer of CFRP composite was $1 \mathrm{~mm}$. Strengthened specimens were supported in a vertical position for application of the CFRP fabric reinforcement. Concrete edges to be wrapped were ground to a minimum radius of $25 \mathrm{~mm}$. Surfaces receiving externally bonded reinforcement were abraded to remove any loose surface material and expose the underlying aggregate in order to ensure good bond. Application was by a manual layup procedure in accordance with the manufacturer's guidance (Sika Ltd. 2006; 2008). 
The concrete mix consisted of local coarse aggregate (12 mm maximum size), fine aggregate and ordinary Portland cement (CEM II 32.5). Concrete cube compressive and split cylinder tensile strengths at testing are shown in Table 2. The specimens were cast on their sides in timber formwork which was removed approximately 24 hours after casting. Specimens were then cured in air alongside their respective test cubes at ambient laboratory temperature.

\section{Specimens}

Specimens were labelled so as to indicate wrap type, number of links, and number of FRP layers.

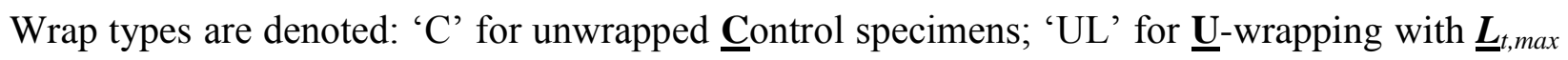

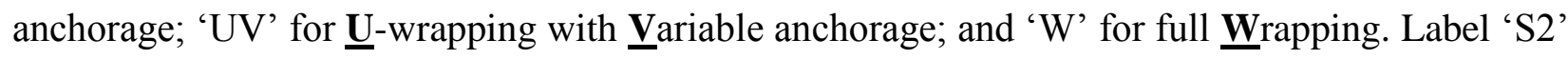
denotes internal $\underline{\mathbf{S}}$ teel reinforcement provision of $\underline{\mathbf{2}}$ links. Labels 'F0', 'F1', 'F2' and 'F3' denote $\underline{F} R P$ reinforcement provision of $\underline{\mathbf{0}}, \underline{\mathbf{1}}, \underline{\mathbf{2}}$ and $\underline{\mathbf{3}}$ layers respectively. For example, specimen $\mathrm{UL} / \mathrm{S} 2 / \mathrm{F} 1$ is a $\mathrm{U}$-wrapped specimen with $L_{t, \max }$ anchorage, having 2 steel links and 1 layer of FRP.

Three un-strengthened specimens were tested. Specimens C/S2/F0a-c were triplicate control specimens with two $6 \mathrm{~mm}$ diameter internal steel links and a target concrete compressive cube strength, $f_{c u}$, of $50 \mathrm{MPa}$. Six strengthened specimens were also tested. Strengthened specimens all contained two $6 \mathrm{~mm}$ internal steel links and had a target $f_{c u}$ of $50 \mathrm{MPa}$ as per the unstrengthened control specimens. Strengthened specimens with three different CFRP configurations were tested. W specimens were fully wrapped with 1, 2, or 3 layers of CFRP, each layer being provided with a $200 \mathrm{~mm}$ lap on one of the non-test faces (Figure 4). UL specimens were U-wrapped with either 1 or 2 layers of CFRP. The vertical sides of the U-wrap were diagonally trimmed such that the anchorage length above the intended failure plane was uniform (Figure 4). The anchorage length was $70 \mathrm{~mm}$ for 1 layer, and $90 \mathrm{~mm}$ for 2 layer, 
marginally longer than the respective $L_{t, \max }$ of $60 \mathrm{~mm}$ and $85 \mathrm{~mm}$ calculated according to TR55

(Table 1) in order to allow surface mounted strain gauges to be located at the $L_{t, \max }$ distance. The UV specimen was U-wrapped with 1 layer of CFRP. The vertical sides of the U-wrap were not trimmed, providing the CFRP with an anchorage beyond the intended failure plane that varied linearly from 70-190 mm (Figure 4). For the UL and UV specimens, the wrap was provided as a single $120 \mathrm{~mm}$ band. For the fully wrapped specimens, the wrap was provided across the 140 mm wide test zone as two $60 \mathrm{~mm}$ bands with a $20 \mathrm{~mm}$ slot 'window' in between to allow the path of the diagonal crack to be observed during testing. Specimen concrete strengths and reinforcement combinations are summarised in Table 2.

\section{Test setup}

Testing was carried out in an Amsler column testing rig. Concentric vertical load was applied from below through pinned top and bottom supports. Initial loading was applied manually by lowering the reaction frame in order to achieve good contact with the specimen; thereafter loading proceeded by incremental displacement and continued until near-complete separation of the two halves led to concern as to the stability of the arrangement, at which point the tests were terminated.

A typical instrumentation arrangement is detailed in Figure 5. Vertical displacements and loads were measured internally by the test rig. Horizontal displacements were measured directly across the test zone using surface mounted linear potential displacement transducers (LPDT). Strain gauges were also attached to the internal steel reinforcement at mid-leg height and, for strengthened specimens to the external CFRP reinforcement at the expected level of formation of the diagonal crack and, at intervals along the anchorage length in order to allow comparison with the strains at crack level. The mid-leg position of the strain gauges on the steel reinforcement 
places the gauges at an offset of approximately $35 \mathrm{~mm}$ from the expected failure interface, this small offset was thought appropriate to reduce damage to the strain gauges while obtaining a reasonable estimate of the strain near the crack.

\section{EXPERIMENTAL RESULTS AND DISCUSSION}

\section{Observed behaviour}

Load-displacement behaviour for the U-wrapped and fully wrapped specimens, as well as the control specimens, are shown in Figures 6a and 6b. All specimens displayed two distinct phases of behaviour; a linear elastic phase prior to an abrupt tensile rupture of the concrete and the formation of a single diagonal crack along the intended failure plane; followed by a non-linear phase dominated by the behaviour of the reinforcement. Generally, specimens behaved as expected, with rotations only occurring towards the latter portion of the tests. However, specimen $\mathrm{C} / \mathrm{S} 2 / \mathrm{F} 0 \mathrm{~b}$ suffered from considerable in plane asymmetric rotation shortly after cracking with the specimen hinging around the bottom corner of the test zone. This was possibly due to a misalignment in the test set-up but the underlying reasons for this atypical behaviour remain unclear. However, the conditions along the shear plane could not be considered to be uniform after cracking and the post cracking behaviour of this specimen is therefore not suited for comparison with the strengthened specimens.

For the un-strengthened specimens $\mathrm{C} / \mathrm{S} 2 / \mathrm{F} 0 \mathrm{a}-\mathrm{c}$, and the U-wrapped UL specimens, the cracking load $F_{c r}$ also constituted the peak load attained. In both UL/S2/F1 and UL/S2/F2 the CFRP detached immediately upon formation of the diagonal crack. The CFRP became detached due to a failure of the underlying concrete, rather than by rupture of the CFRP or loss of bond at the interface between the CFRP and the concrete surface (see Figure 7). This failure mode is commonly observed in the testing of U-wrapped beams and post-test inspection showed 
substantial concrete including whole aggregate still bonded to the CFRP, indicating that this was not a failure of the resin to form a good bond with the underlying concrete. No discernible contribution was made by the CFRP U-wrap after the formation of the diagonal crack.

The fully wrapped $\mathrm{W}$ specimens reached an initial peak load immediately prior to cracking. The wrapping makes it difficult to determine whether this initial cracking was initially distributed or whether a dominant through-crack forms at this time. However, removal of the CFRP post-test indicates that, ultimately, a clear dominant crack along the expected failure plane does form, as is the case for the un-strengthened and U-wrapped specimens. A second peak is reached at rupture of the well anchored CFRP. For W/S2/F2 and W/S2/F3, this second peak represented the peak load attained, exceeding $F_{c r}$ by 10 and $25 \mathrm{kN}$ respectively.

\section{Load sharing behaviour}

The average strain gauge measurements from all three $\mathrm{W}$ specimens and from C/S2/F0c were used to calculate the load share between the concrete, steel and CFRP in the fully wrapped and un-strengthened configurations. This was possible up to a vertical displacement of the order of 2$3 \mathrm{~mm}$ at which point the strain gauges on the steel in most specimens appeared to become damaged. The apparent contributions of the steel, $F_{s}$, and the CFRP, $F_{f r p}$, were determined from strain measurements taken at or near the failure plane, until the failure of the strain gauges. As discussed previously, the strain gauges on the steel reinforcement were slightly offset from the crack plane. However, since the bars were smooth, the readings are likely to be reasonable representations of the strains at the crack. The concrete contribution is assumed to be the difference between the total force $F$ and the sum of $F_{s}$ and $F_{f r p}$ for a given displacement. For the following plots, local vertical displacements across the test zone were obtained by correcting for elastic deformation of the overall specimen. For all four specimens considered in Figure 8, peak 
load was reached or neared prior to the loss of the steel strain gauges meaning that a fairly complete picture of load sharing behaviour can be obtained.

Steel strain gauge readings for the UL and UV specimens and specimen C/S2/F0a were generally erratic, indicating damage to the strain gauges during the abrupt cracking of the specimens. However, the observed separation of the underlying concrete at cracking of the UL specimens indicates that the CFRP U-wrap does not provide any contribution after cracking indicating that the load carrying mechanism after cracking is the same as for the control specimens.

Figure 8 indicates that for the un-strengthened specimen, the steel carries the whole applied load, meaning that the concrete provides no contribution to resistance after initial cracking. This indicates that, since the full capacity of the steel reinforcement is utilised in carrying the load directly, there is no further capacity in the steel available to provide a restraining force necessary to engage an aggregate interlock or shear frictional component of resistance. The apparent absence of a concrete contribution $F_{c}$ in this arrangement should not necessarily be taken to indicate the absence of a concrete contribution $V_{c}$ in a beam situation, where $V_{c}$ may be expected to include a significant contribution from the concrete above the neutral axis in the compression zone. The addition of fully wrapped CFRP does appear to engage a small concrete contribution. This is seen for all three fully wrapped specimens. It is further seen that with the addition of two and three layers of fully wrapped CFRP, the load in the steel is reduced in comparison to the control specimen.

The load share between the steel and CFRP would be expected to relate to the relative stiffness of the two reinforcements. Although the nominal relative stiffness of the internal steel and external CFRP reinforcements in terms of the relationship between $A_{s} E_{s}$ and $A_{f r p} E_{f r p}$ only become approximately equal in the 3 layer specimen (Table 2), a more realistic relative stiffness in terms 
of $A_{s} E_{s} / L_{d b, s}$ and $A_{f r p} E_{f r p} / L_{d b, f r p}$ is dependent both on the respective debonded lengths and on any tension stiffening effects of concrete bonded to the CFRP. Tap testing on the specimens at the end of testing indicated a typical debonded CFRP length of approximately $140 \mathrm{~mm}$. If the debonded length for the smooth reinforcement is assumed to be the full $220 \mathrm{~mm}$ height of the stirrup then the relative stiffness of the reinforcements become approximately equal in the 2 layer specimen. Allowing for the likelihood that the debonded CFRP length was somewhat less for the portion of the test shown in Figure 8 than at the cessation of testing, and considering the potential for tension stiffening effects, it seems likely that the effective equivalence of stiffness would occur at a CFRP provision somewhere between that provided by 1 and 2 layers. This is borne out by the inversion of the relative force contributions of the steel and the CFRP between W/S2/F1 and W/S2/F2 (Figure 8).

For a more detailed assessment of the load displacement behaviour, it is necessary to account for variation in $f_{c u}$ between specimens. In all cases the majority of the visible aggregate remained intact with the failure plane occurring through the cementitious matrix and at the aggregate matrix interface. The tortuosity of the shear plane is thus assumed to be typical of 'normal' strength concrete, and to be comparable across the specimens. The brittle, tensile nature at cracking indicates that concrete tensile strength may provide a sensible basis for normalisation. A value for load $F^{\prime}$ with concrete strength normalised by the ratio of the concrete tensile strength, $f_{c t}$, to that of the mean for the series, $\overline{f_{c t}}$, is obtained by:

$$
F^{\prime}=F_{s}+F_{f r p}+\frac{F_{c}}{f_{c t} / \overline{f_{c t}}}
$$


In Figure 9, the load-displacement relationship at the failure interface is plotted. Results of specimens $\mathrm{C} / \mathrm{S} 2 / \mathrm{F} 0 \mathrm{a}$ and $\mathrm{C} / \mathrm{S} 2 / \mathrm{F} 0 \mathrm{c}$ are averaged to provide a control value for the purposes of comparison designated 'Control'. Figure 9(a) indicates that the FRP U-wrap, provided with an $L_{t, \max }$ anchorage in accordance with current UK guidance has no discernible effect on the postcracked load displacement behaviour of the specimen. Conversely, Figure 9(b) indicates that fully wrapped CFRP has a significant effect on post-cracked load-displacement behaviour, and that increasing the CFRP ratio increases the effect. Thus it would indicate that the provision of suitable anchorage is an important factor in mobilising the contribution of the CFRP. This is shown in Figure 9(c) where the varying anchorage conditions are compared. The UV specimen can be seen initially matching the behaviour of its fully wrapped equivalent W/S2/F1 before progressively de-bonding, starting at the shorter, $L_{t, \max }$ end. Resistance is correspondingly reduced to little more than that of the UL and C specimens, as the vertical displacement increases from approximately 1.5 to $2.5 \mathrm{~mm}$. A small contribution is seen from the portion of CFRP that remained bonded at the end of the crack corresponding to the longer anchorage length for a further increment, up to a vertical displacement of approximately $3.5 \mathrm{~mm}$. Thereafter the specimen behaved as the UL and C specimens. That the CFRP contribution of the UV specimen initially matched that of the $\mathrm{W} /$ specimen, indicates that the bonded unwrapped end condition can be suitable to engage the CFRP contribution but that an $L_{t, \max }$ anchorage, is insufficiently strong to sustain it such that a measurable transfer of load could take place.

The strain gauge results indicated that the load prior to cracking is primarily carried by the uncracked concrete. This is not unexpected given the high stiffness of the un-cracked concrete section relative to both the internal and the external reinforcement. The high degree of scatter when shear stresses at cracking $\tau_{c r}$ (equal to $\sigma_{c r}$ in the case of $\theta=45^{\circ}$ ) are plotted against 
concrete strength (Figure 10a), makes it difficult to draw strong conclusions about the relationship between concrete strength and uncracked shear strength over this small range of concrete strengths. The plot of the normalised cracking shear stress against FRP reinforcement ratio in Figure $10 \mathrm{~b}$ shows a relatively weak trend $\left(\mathrm{R}^{2}=0.68\right)$ between these parameters, indicating that there may be a small enhancement in uncracked shear strength with increasing FRP provision. This does not correspond to a direct contribution in resistance from the CFRP, as determined by strains (c.f. Table 3), but would rather appear to be the result of an enhancement of the concrete, perhaps by impeding the formation or propagation of an initiating crack at a point of local weakness or higher residual stresses due to shrinkage restraint.

The three un-strengthened specimens displayed a variation in normalised cracking load from 91$119 \mathrm{kN}$. In evaluating the possible contribution of FRP to the uncracked shear strength of the specimens, the underlying variability in the unstrengthened specimens should not be overlooked. Quantifying this variation in a statistically robust manner would require a larger data set of unstrengthened specimens.

\section{Implications for design approaches}

The experimental results have a number of implications that should be considered when formulating design approaches both for shear strengthened beam design and more generally, when designing or assessing shear transfer at an interface.

For the combination of shear and tension investigated in these tests, the concrete contribution to resistance after initial cracking in the un-strengthened and U-wrapped specimens was negligible. This indicates that a concrete contribution should not be considered in determining the cracked load capacity at an un-strengthened or U-wrapped interface with smooth internal reinforcement subject to similar combinations of shear and tension. However, a concrete contribution to 
resistance was observed in the fully wrapped specimens. This may also be the case for specimens reinforced with deformed bars, where enhanced bond may lead to local reductions in crack width and the possible formation of a secondary local concrete resistance mechanism as postulated by Walraven and Reinhardt (1981).

The results highlight the importance of ensuring that the CFRP is well anchored if it is to be considered in design. The provision of anchorage lengths in accordance with guidance documents, engaged no discernible contribution from the CFRP U-wrap. Providing anchorage beyond $L_{t, m a x}$ did engage a contribution from the CFRP. This indicates that the methodology for determining bonded anchorage lengths should be revisited to ensure that the test conditions adequately reflect the debonding behaviour at a diagonal crack in initially un-cracked concrete. The use of smooth reinforcing bar allows the steel to strain more uniformly over the leg height when compared with deformed bars so is likely to provides a suitable adverse case for determining the required anchorage length for reinforced concrete.

For the fully wrapped specimens the contribution to resistance provided by the steel and the CFRP was broadly in line with their design values of tensile resistance assuming yielding of the steel and rupture of the CFRP (Table 4). This indicates that, for well anchored reinforcement, methods of superposition may be appropriate.

The variability in the cracking load, notwithstanding the possibility of an enhancement from the CFRP, can be seen as supporting Mast's (1968) contention that it is improper to rely on the presence of an un-cracked concrete tensile contribution for the purposes of strength design. However, the uncracked shear strength, in all cases except the quite heavily reinforced W/S2/F2 and W/S2/F3, exceeded that of the cracked shear strength. Hence neglecting this pre-cracking 
resistance may introduce conservatism in the design of reinforced elements that remain uncracked.

The load share plots (Figure 8) indicate that the presence of the CFRP wrap did influence the strain behaviour of the internal steel reinforcement. For a given displacement, the strains in the steel were reduced in the more heavily wrapped specimens compared to the un-strengthened and single layer wrapped specimen. This provides further evidence that, at least in the case of smooth internal reinforcement, the CFRP strengthening mechanism can affect the underlying concrete and steel resistance mechanism. The presence of CFRP strengthening may prevent yield of the reinforcement prior to failure of the CFRP, meaning that in such cases $V_{s}$ may be less than that calculated assuming yielding of the steel.

\section{FURTHER RESEARCH}

This study has investigated the behaviour of specimens forming a failure plane at $-45^{\circ}$. Further research is needed to explore the behaviour of specimens forming a failure plane at different angles and with different combinations of internal and external reinforcement. Further investigation for U-wrapped specimens with a range of uniform anchorage lengths will be necessary to establish robust empirical values in order to evaluate the appropriateness of existing bond and bond-slip models for external FRP strengthening in conjunction with an understanding of the implications of the debonded length beyond the failure plane for the force realised in the FRP.

\section{SUMMARY AND CONCLUSIONS}

The results of an experimental series of nine un-strengthened and strengthened 'modified' pushoff specimens have been presented, covering a range of CFRP thicknesses and wrapping 
configurations. Results indicate that neither concrete nor CFRP makes a significant contribution to post-cracked resistance in un-strengthened and U-wrapped specimens with a uniform anchorage length of $L_{t, \max }$. Both the CFRP, and to a lesser extent the concrete, are shown to contribute to post-cracked resistance in the fully-wrapped specimens. The CFRP contribution in the fully wrapped specimens is broadly in line with the CFRP design strengths.

\section{ACKNOWLEDGEMENTS}

The authors wish to gratefully acknowledge the financial support of the UK Engineering and Physical Sciences Research Council (EPSRC) through grant EP/I018972/1. The authors also wish to extend their sincere thanks to Jan Nilsson, Martin Touhey and the staff of the University of Cambridge Structures Research Lab for their invaluable assistance in carrying out the experimental programme reported above. Additional data related to this publication is available at the University of Cambridge institutional data repository: https://www.repository.cam.ac.uk/handle/1810/249023.

\section{REFERENCES}

AASHTO (American Association of State Highway Transportation Officials). (2008). "Bridging the Gap: Restoring and Rebuilding the Nation's Bridges." Washington D.C.

ACI (American Concrete Institute). (2008). "Guide for the Design and Construction of Externally Bonded FRP Systems for Strengthening Concrete Structures", ACI 440.2R-08, Farmington Hills, USA.

Belarbi, A., Bae, S-W., and Brancaccio, A. (2012). "Behavior of Full-scale RC T-beams Strengthened in Shear with Externally Bonded FRP Sheets." Constr. Build. Mater., 32, 2740. 
Birkeland, P. W., and Birkeland, H. W. (1966). "Connections in Precast Concrete Construction.” J. Am. Concrete I., Proc., 63(3), 345-368.

Bousselham, A., and Chaallal, O. (2006). "Behavior of Reinforced Concrete T-Beams Strengthened in Shear with Carbon Fiber-Reinforced Polymer-An Experimental Study." ACI Struct. J., 103(3), 339-347.

Chen, G. M., Teng, J. G., and Chen, J.F. (2012). "Process of Debonding in RC Beams ShearStrengthened with FRP U-strips or Side Strips.” Int. J. Solids Struct., 49, 1266-1282.

The Concrete Society. (2004). "Design guidance for strengthening concrete structures using fibre composite materials" ( $2^{\text {nd }}$ Edition). Technical Report No. 55, Camberley, UK.

The Concrete Society. (2012). "Design guidance for strengthening concrete structures using fibre composite materials" ( $3^{\text {rd }}$ Edition). Technical Report No. 55, Camberley, UK.

Denton, S.R., Shave, J.D., and Porter, A.D. (2004) "Shear Strengthening of Reinforced Concrete Structures Using FRP Composite", Advanced Polymer Composites for Structural Applications in Construction, Hollaway, L.C., Chryssanthopoulos, M.K., and Moy, S.S.J. (Eds.) Woodhead Publishing Limited, Cambridge, UK, 134-143.

Dirar, S., Lees, J., and Morley, C. (2012). "Precracked Reinforced Concrete T-Beams Repaired in Shear with Bonded Carbon Fiber-Reinforced Polymer Sheets", ACI Struct. J., 109(2), 215-224.

fib (International Federation for Structural Concrete). (2001). "Externally Bonded FRP Reinforcement for RC Structures.” Bulletin 14, Lausanne, Switzerland.

Grusova, M., Ibell, T. J., Darby, A.P, and Evernden, M. (2013). "Shear Transfer in CFRP Strengthened Reinforced Concrete." Advanced Composites in Construction (ACIC) 2013 Conference Proc., 43-54. 
Harries, K. A., Zeno, G., and Shahrooz, B. (2012). "Toward and Improved Understanding of Shear Friction Behaviour.” ACI Struct. J., 109(S73), 835-844.

Haskett, M., Oehlers, D. J., Mohamed Ali, M. S. and Wu, C. (2009) "Yield Penetration Hinge Rotation in Reinforced Concrete Beams." J. Struct. Eng., 135(2), 130-138.

Hofbeck, J. A, Ibrahim, I. O., and Mattock, A. H. (1969). "Shear Transfer In Reinforced Concrete." J. Am. Concrete I., Proc., 66(2), 119-128.

Khalifa, A., Gold, W., Nanni, A., and Abel-Aziz, M. (1998). "Contribution of Externally Bonded FRP to the Shear Capacity of RC Flexural Members," J. Compos. Constr., 2(4), 195-203.

Lima, J. L., and Barros, J. A. (2011). "Reliability Analysis of Shear Strengthening Externally Bonded FRP Models." Struct. Build., 164(SB1), 43-56.

Mast, R. F. (1968) “Auxiliary Reinforcement in Concrete Connections.” J. Struct. Div. ASCE, Proc., 94(ST6), 1485-1504.

Mattock, A. H. (1974). "Shear Transfer In Concrete Having Reinforcement At An Angle To The Shear Plane.” ACI Publication SP-42: Shear in Reinforced Concrete, 17-42.

Mattock, A. H., and Hawkins, N. M. (1972). "Shear Transfer In Reinforced Concrete - Recent Research.”J. PCI, 17(2), 55-75.

Mattock, A. H., Johal, L., and Chow, H. C. (1975). "Shear Transfer in Reinforced Concrete with Moment or Tension Acting Across the Shear Plane.” J. PCI, 20(4), 76-93.

Mattock, A. H., Li, W. K., and Wang, T. C. (1976). "Shear Transfer in Lightweight Reinforced Concrete." J. PCI, 21(1), 20-39.

Mofidi, A., and Chaallal, O. (2014). "Effect of Steel Stirrups on Shear Resistance Gain Due to Externally Bonded Fiber-Reinforced Polymer Strips and Sheets.” ACI Struct. J., 111(2), 353-362. 
Middleton, C. R. (2004). "Bridge Management and Assessment in the UK." Proceedings of Austroads 5th Bridge Conference, Austroads, Australia, 16.

Neubauer, U., and Rostasy, F.S. (1997) "Design Aspects of Concrete Structures Strengthened with Externally Bonded CFRP Plates." Proc. of the 7th International Conference on Structural Faults and Repair, ECS Pub, Edinburgh, UK, 2, 109-118.

Sika Ltd. (2006). SikaWrap®-230C Product Data Sheet.

Sika Ltd. (2008). Sikadur®-330 Product Data Sheet.

Triantafillou, T. C., and Antonopoulos, C. P., (2000). "Design of concrete flexural members strengthened in shear with FRP.” J. Compos. Constr. 4(4), 198-205.

Walraven, J. C., and Reinhardt, H. W. (1981). "Theory and Experiments on the Mechanical Behaviour of Cracks in Plain and Reinforced Concrete Subject to Shear Loading." Heron, 26(1) 1-68. 


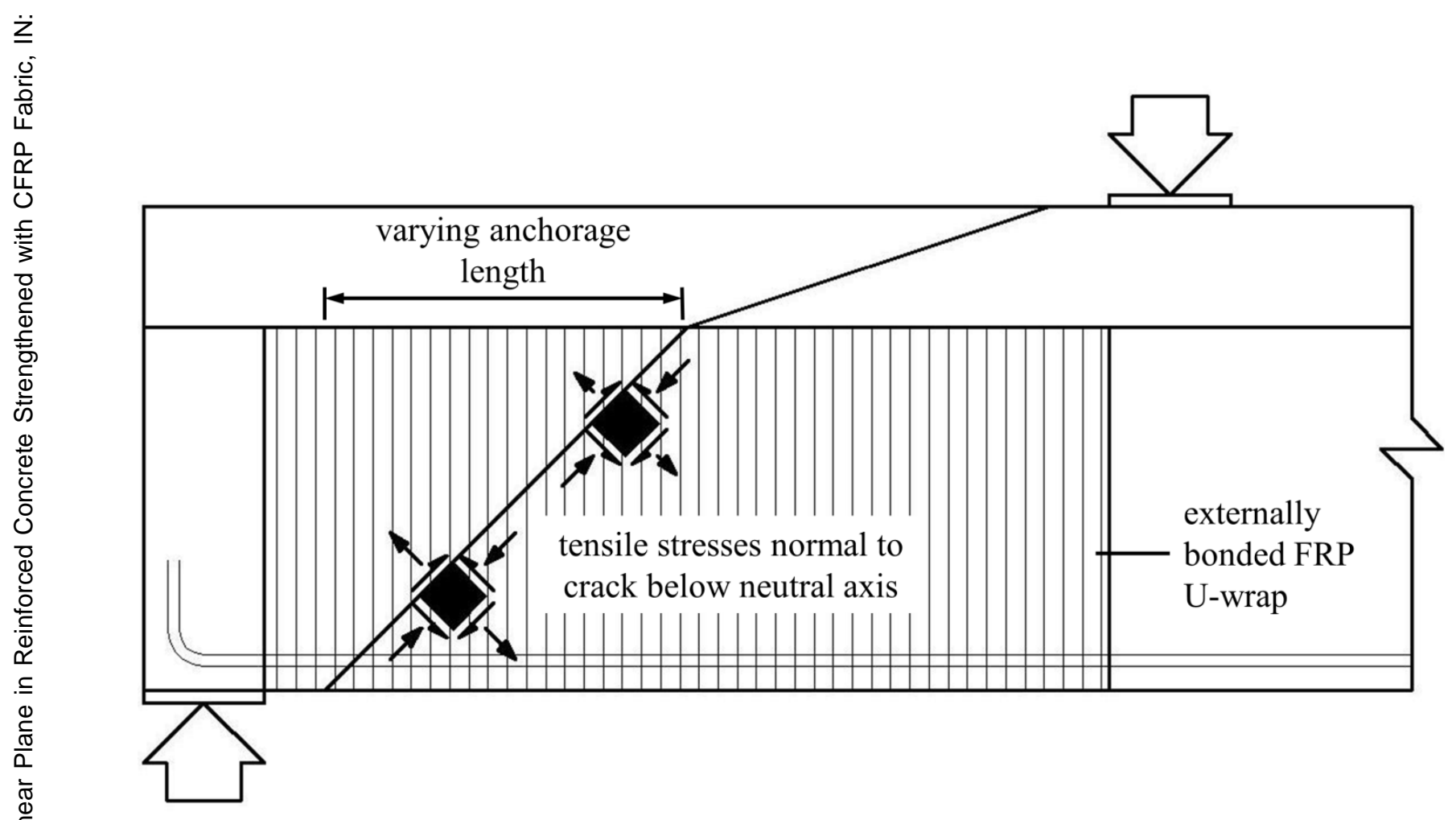

Figure 1 - Variation in tensile normal stresses and FRP anchorage length along a crack 

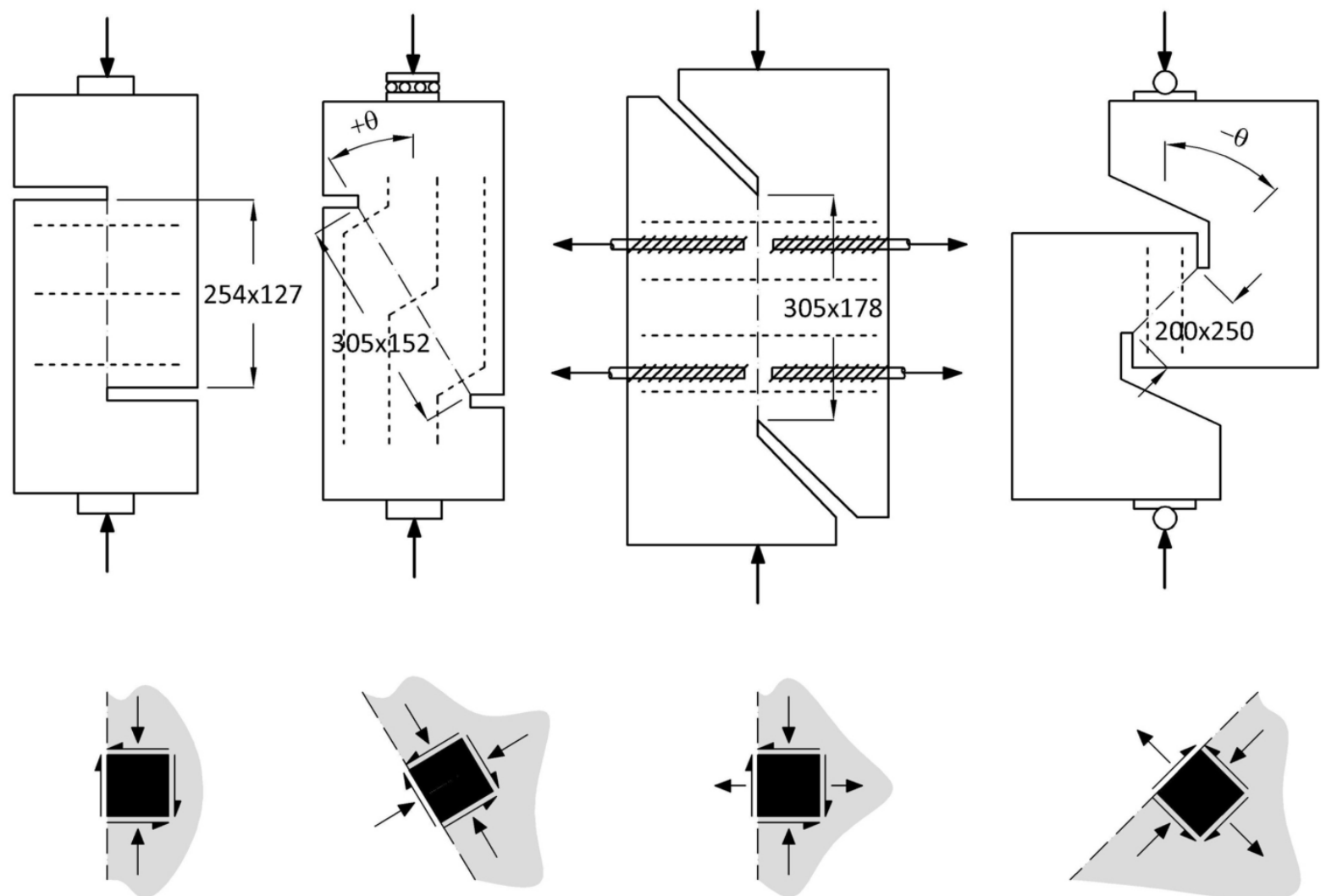

(a)

(b)

(c)

(d)

Figure 2 - Push-off specimens and applied stresses at interface: a) conventional and b) modified +ve $\theta$ (after Mattock \& Hawkins 1972); c) conventional with constant applied tension (after Mattock et al. 1974); and d) modified -ve $\theta$ (not to scale), dimensions in mm 


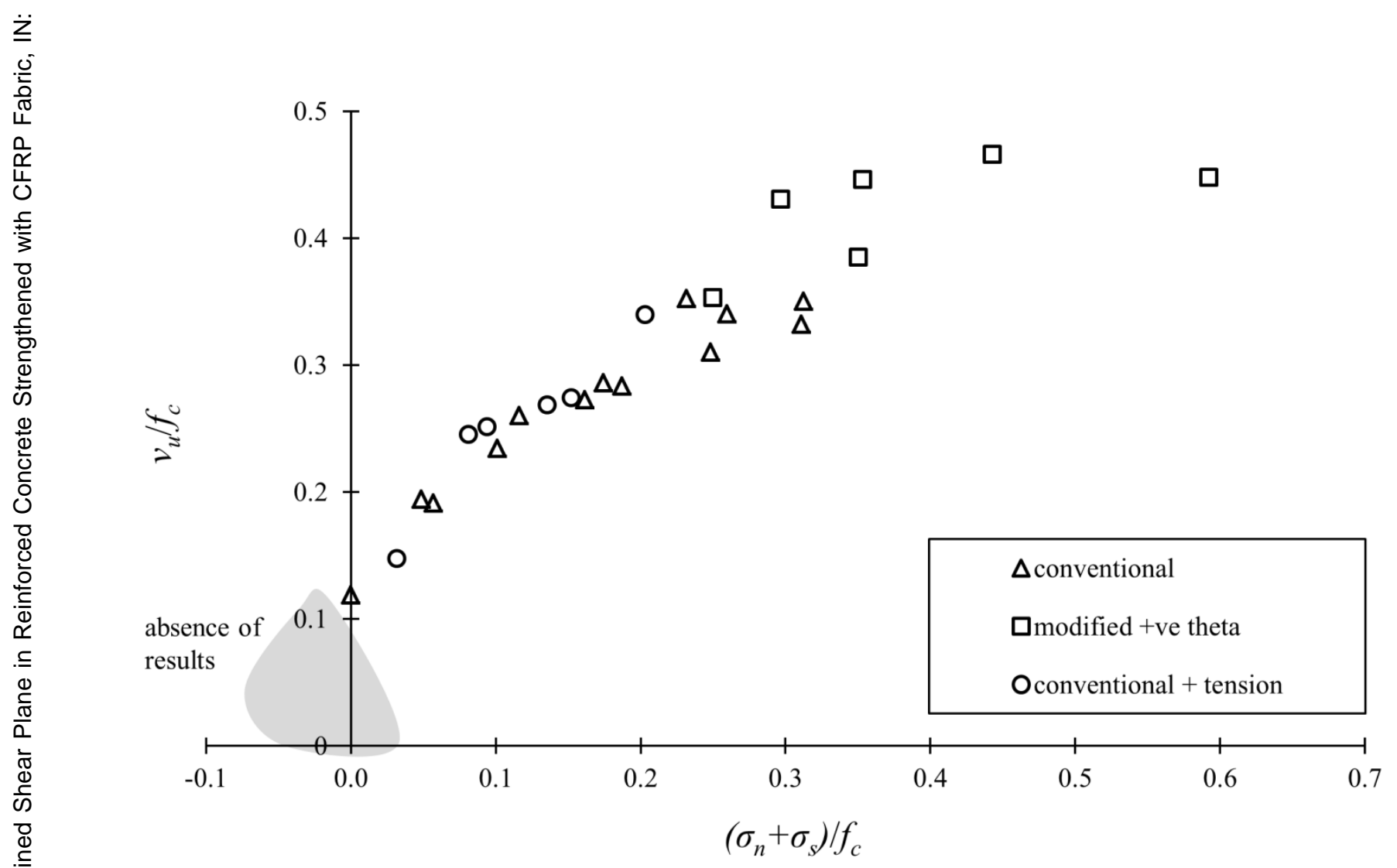

Figure 3 - Normalised plot of ultimate shear capacity of push-off tests subject to combinations of shear and net normal stresses (data from Mattock and Hawkins 1972; Mattock et al. 1975). 

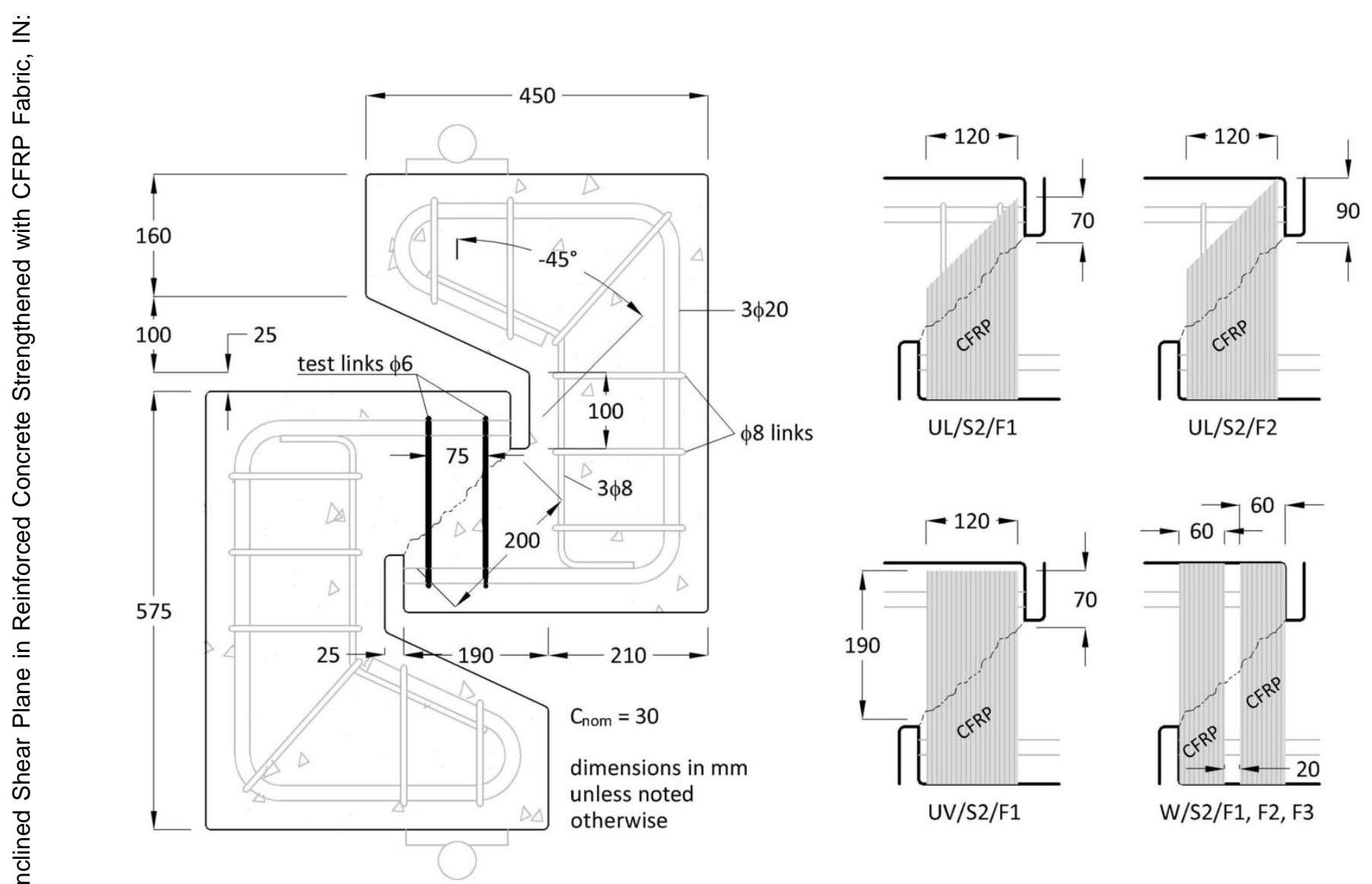

Figure 4 - Modified push-off specimen, -ve $\theta$, designed for this study

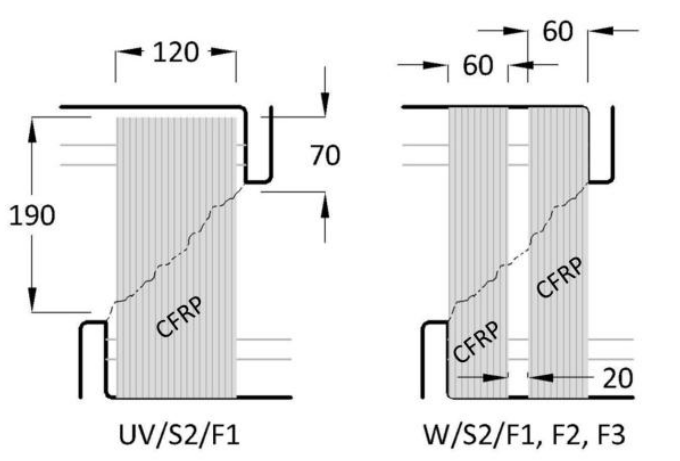



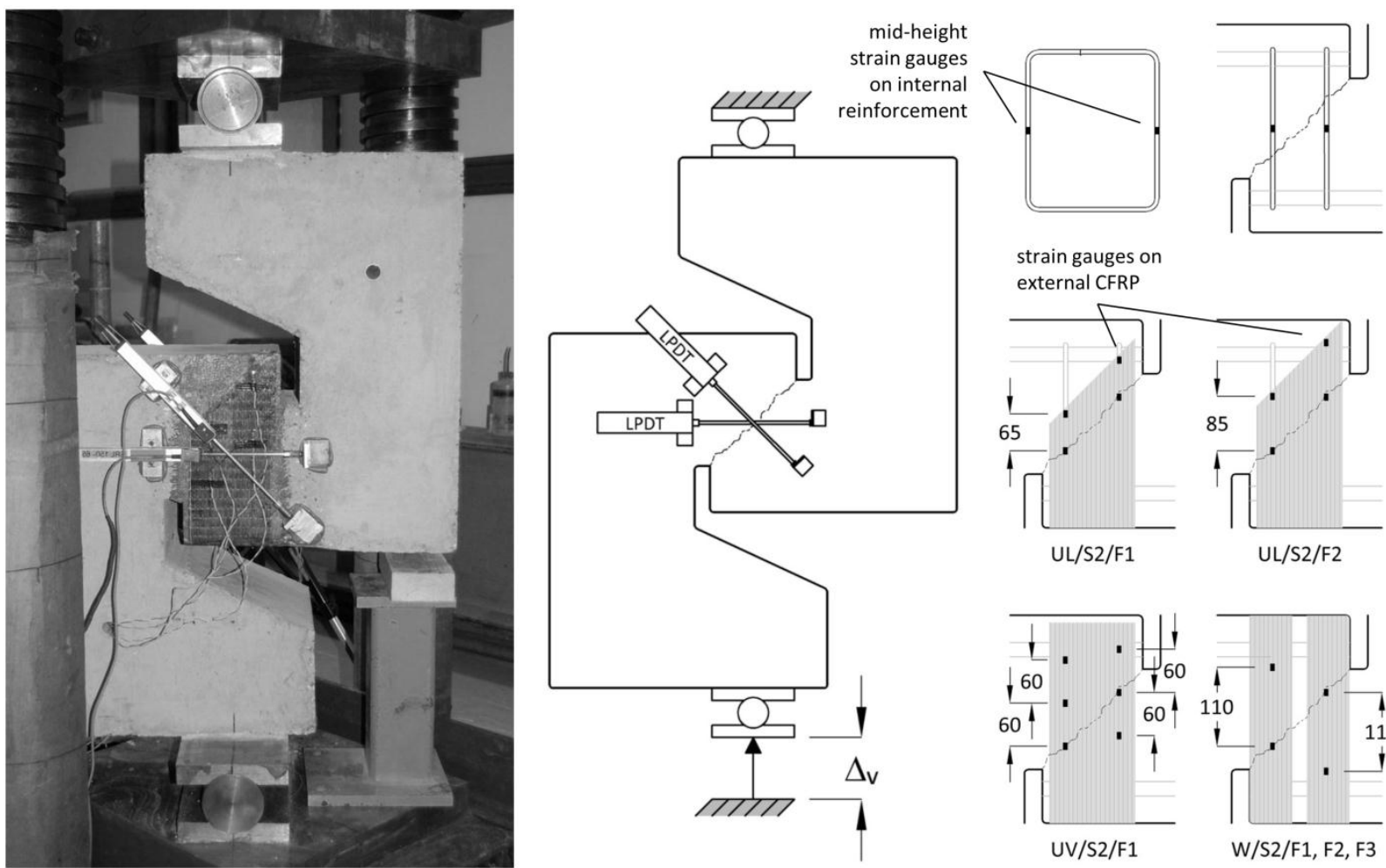

strain gauges on external CFRP
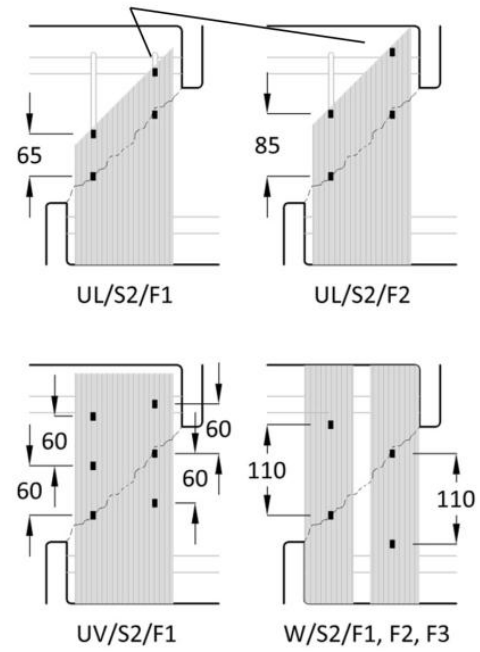

Figure 5 - LPDT and strain gauge arrangement, dimensions in mm 


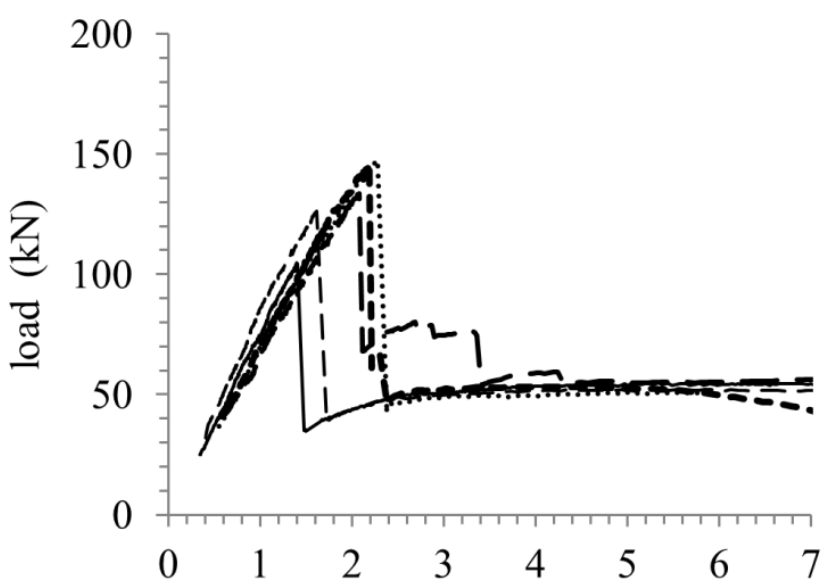

(a)

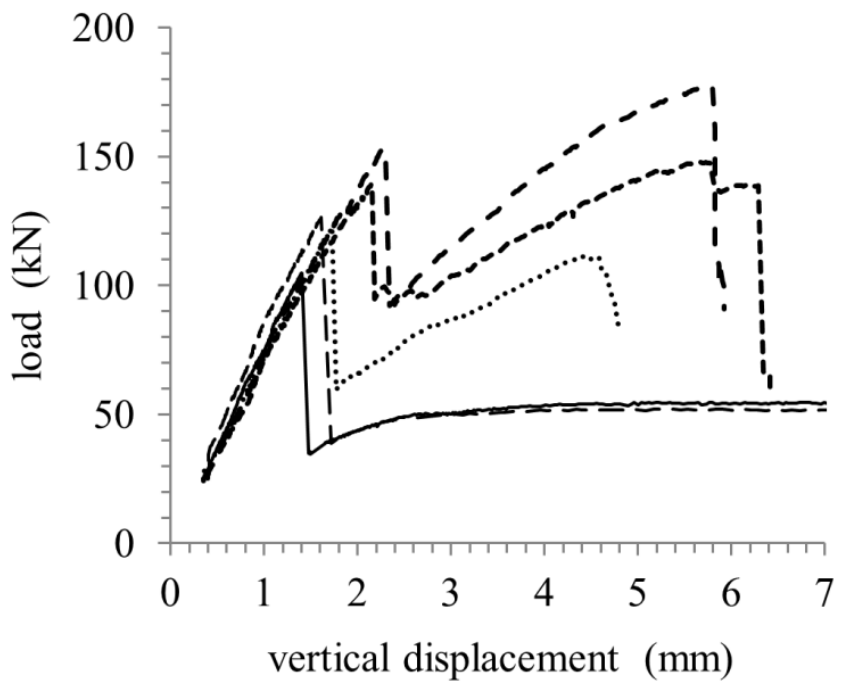

Fully wrapped, varying layers

- - - W-S2-F3

----- W-S2-F2

…… W-S2-F1

$\mathrm{C} / \mathrm{S} 2 / \mathrm{F} 0 \mathrm{a}$

(b)

Figure 6 - Overall load-deflection behaviour a) U-wrapped and b) fully wrapped 

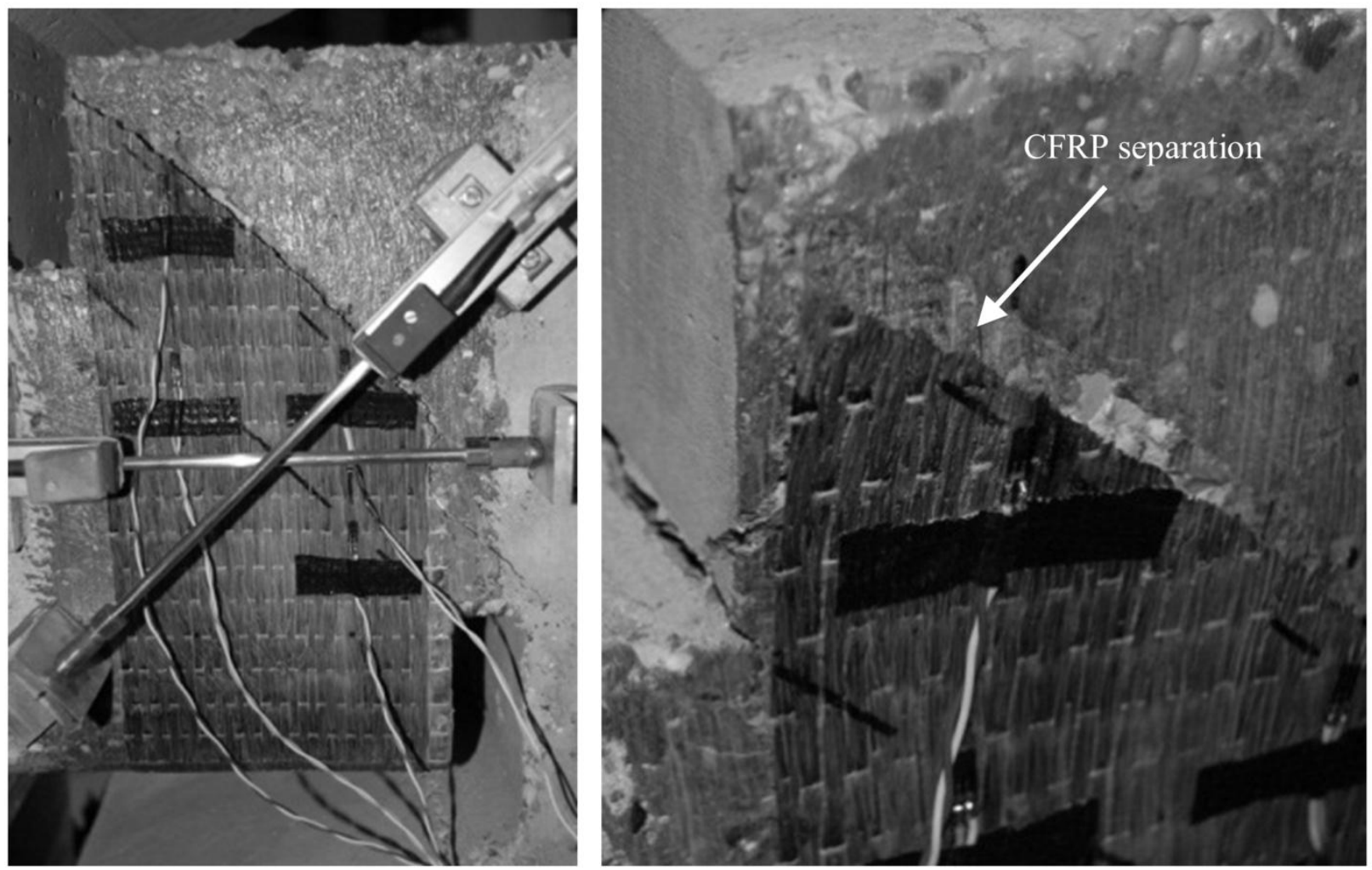

Figure 7 - U-wrapped anchorage separation, similar for both UL specimens 

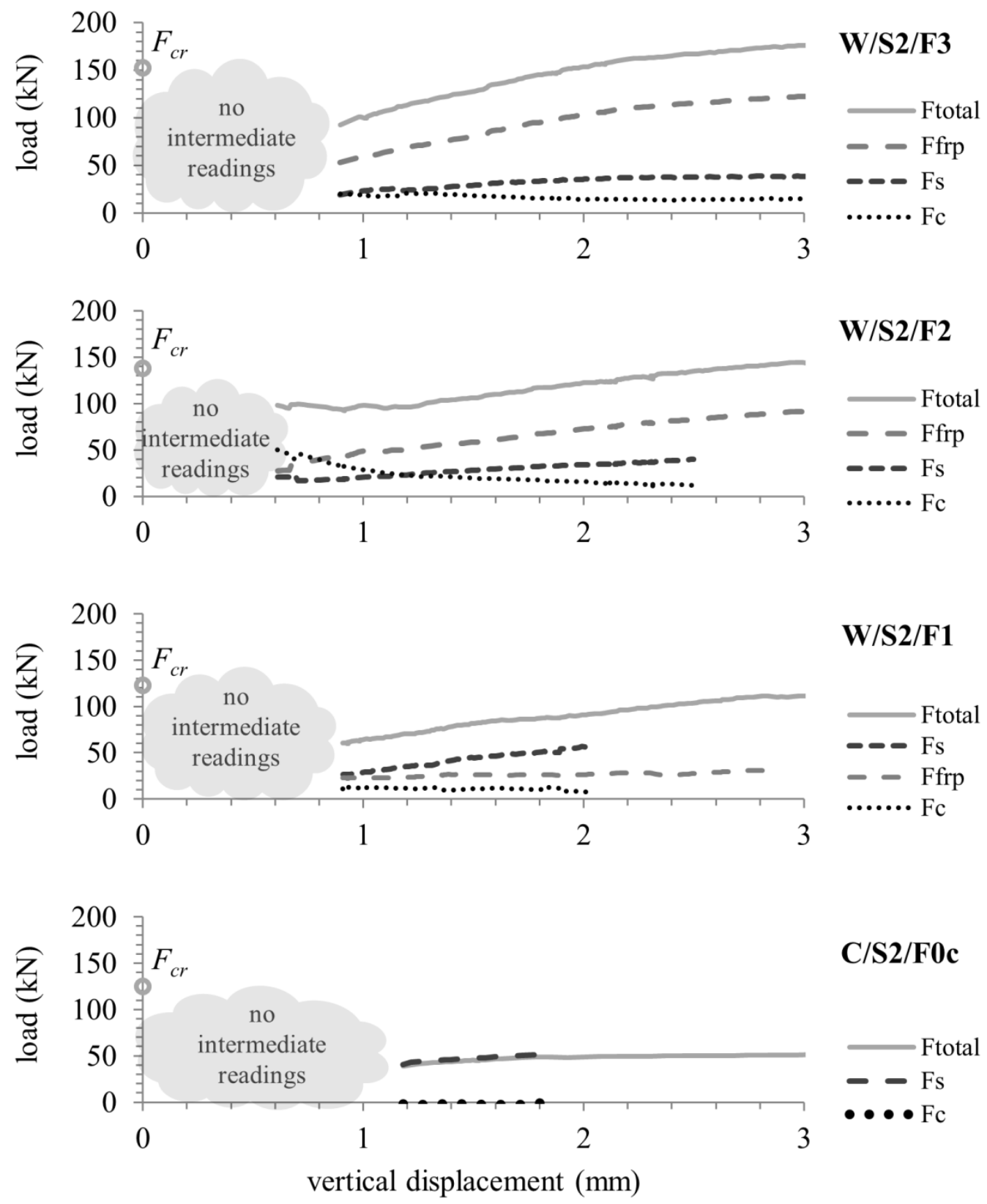

Figure 8 - Share of load in steel $\left(F_{s}\right)$ and CFRP $\left(F_{f r p}\right)$ determined from strain gauges; and concrete $\left(F_{c}\right)$ assumed to carry remainder. 


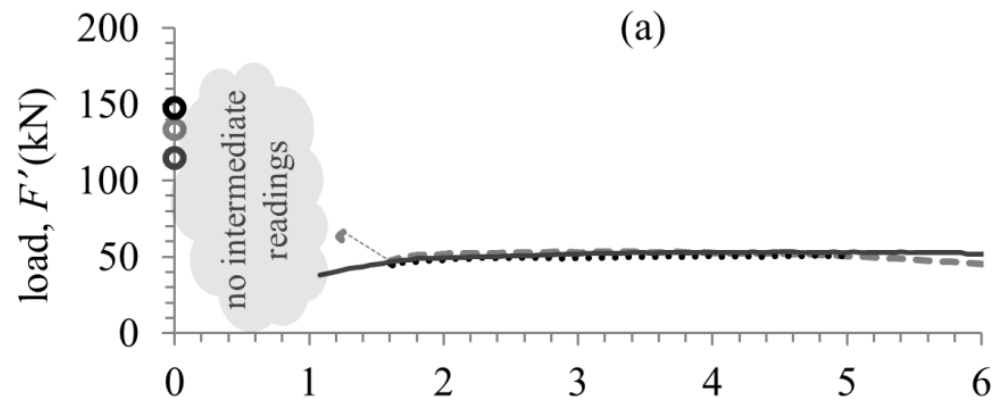

U-wrapped uniform Lt,max anchorage, varying layers

$----\mathrm{UL} / \mathrm{S} 2 / \mathrm{F} 2$

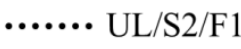
Control
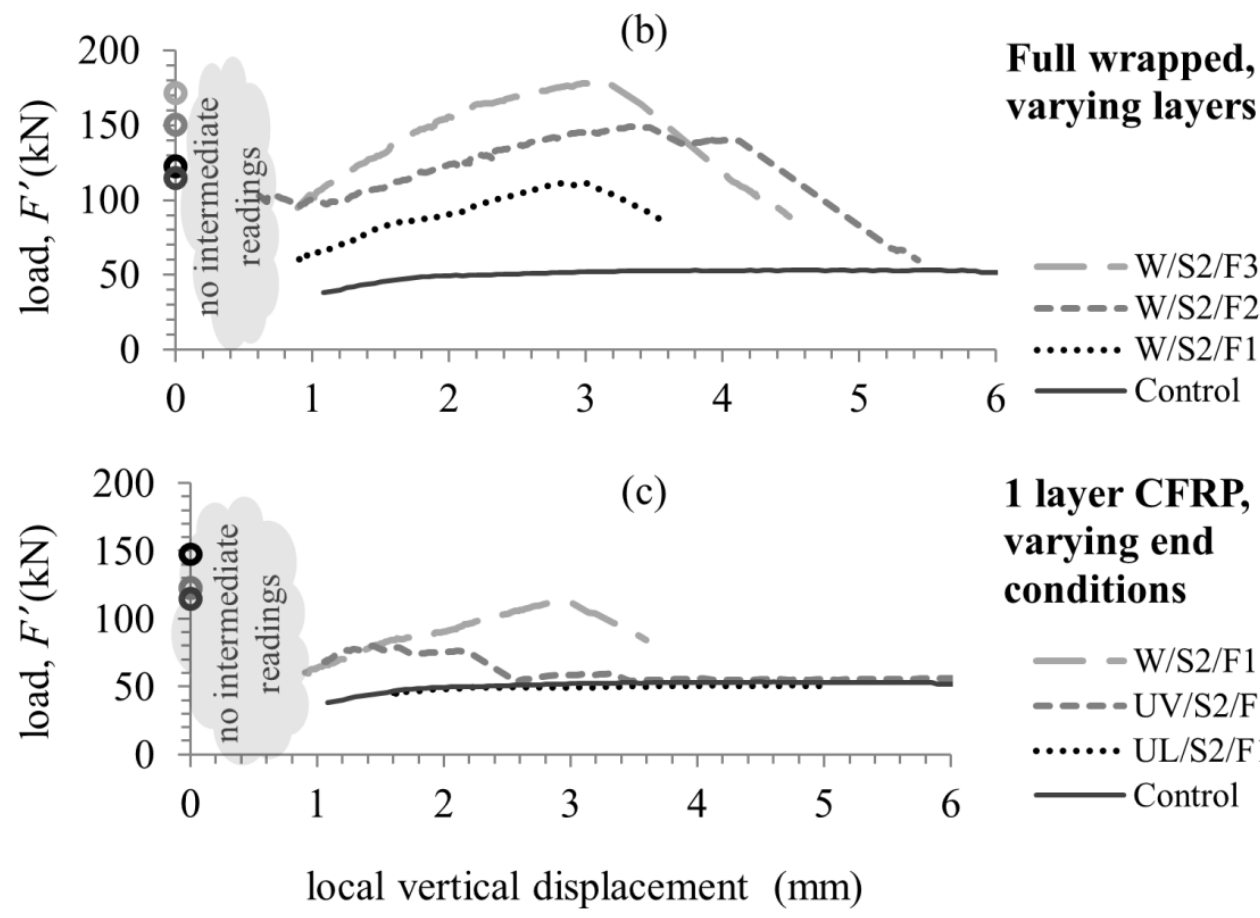

1 layer CFRP, varying end conditions

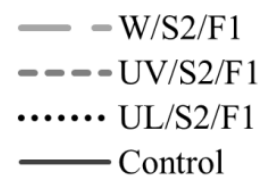

Figure 9 - Load-displacement behaviour local to failure plane 

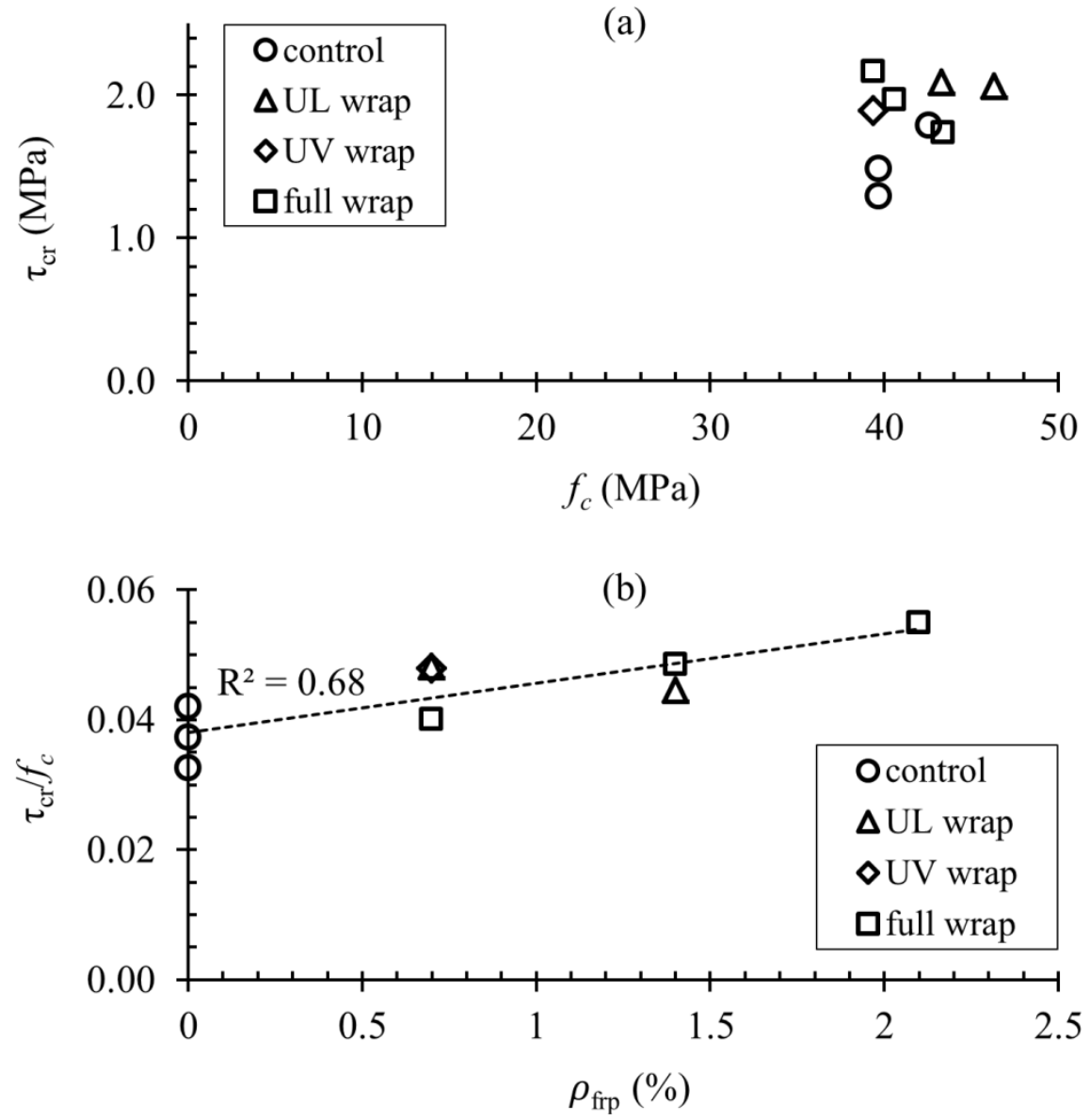

Figure $10-a)$ influence of concrete strength on cracking stress, b) influence of reinforcement percentage on normalised cracking stress 
Table 1 - Expressions and values for maximum effective anchorage length

\begin{tabular}{ccc}
\hline $\begin{array}{c}\text { CFRP } \\
\text { arrangement }\end{array}$ & $\begin{array}{c}L_{e, a c i}-\mathrm{ACI} 440.2 \mathrm{R}- \\
08 \\
(\mathrm{~mm})\end{array}$ & $\begin{array}{c}L_{t, \max }-\mathrm{TR} 55 \\
(\mathrm{~mm})\end{array}$ \\
\hline $\begin{array}{c}\text { Expression } \\
\text { (S.I. unit) }\end{array}$ & $\frac{23300}{\left(n_{F R P} t_{F R P} E_{F R P}\right)^{0.58}}$ & $0.7 \sqrt{\frac{E_{F R P} T_{F R P}}{f_{c t m}}}$ \\
1 layer & 61 & 60 \\
2 layer & 41 & 85 \\
\hline
\end{tabular}

Table 2 - Specimen reinforcement combinations

\begin{tabular}{|c|c|c|c|c|c|c|}
\hline \multirow[b]{2}{*}{ specimen } & \multicolumn{2}{|c|}{ concrete } & \multirow{2}{*}{$\begin{array}{c}\text { steel } \\
\rho_{s} f_{y,}, \\
\mathrm{MPa}\end{array}$} & \multicolumn{3}{|c|}{ CFRP } \\
\hline & $\begin{array}{l}f_{c u}, \\
\mathrm{MPa}\end{array}$ & $\begin{array}{c}f_{c t,} \\
\mathrm{MPa}\end{array}$ & & $\begin{array}{c}\text { FRP } \\
\%\end{array}$ & $\begin{array}{c}A_{s} E_{s} / \\
A_{F R P} E_{F R P}\end{array}$ & $\begin{array}{l}L_{t} \\
\mathrm{~mm}\end{array}$ \\
\hline $\mathrm{C} / \mathrm{S} 2 / \mathrm{F} 0 \mathrm{a}$ & 50 & 3.2 & 1.8 & - & - & - \\
\hline $\mathrm{C} / \mathrm{S} 2 / \mathrm{F} 0 \mathrm{~b}^{\mathrm{a}}$ & 50 & 3.4 & 1.8 & - & - & - \\
\hline $\mathrm{C} / \mathrm{S} 2 / \mathrm{F} 0 \mathrm{c}$ & 53 & 3.6 & 1.8 & - & - & - \\
\hline UL/S2/F1 & 54 & 3.4 & 1.8 & 0.7 & 3.4 & 70 \\
\hline UL/S2/F2 & 58 & 3.7 & 1.8 & 1.4 & 1.7 & 90 \\
\hline $\mathrm{W} / \mathrm{S} 2 / \mathrm{F} 1$ & 54 & 3.4 & 1.8 & 0.7 & 3.4 & full wrap \\
\hline $\mathrm{W} / \mathrm{S} 2 / \mathrm{F} 2$ & 51 & 3.1 & 1.8 & 1.4 & 1.7 & full wrap \\
\hline $\mathrm{W} / \mathrm{S} 2 / \mathrm{F} 3$ & 49 & 3.0 & 1.8 & 2.1 & 1.1 & full wrap \\
\hline UV/S2/F1 & 49 & 3.7 & 1.8 & 0.7 & 3.4 & $70-190$ \\
\hline
\end{tabular}


Table 3 - Test results

\begin{tabular}{|c|c|c|c|c|c|}
\hline \multirow{2}{*}{ Specimen } & \multirow{2}{*}{$\begin{array}{c}\begin{array}{c}\text { Peak } \\
\text { load }\end{array} \\
F_{u} \\
\mathrm{kN}\end{array}$} & \multicolumn{4}{|c|}{ Prior to critical crack } \\
\hline & & $\begin{array}{l}F_{c r} \\
\mathrm{kN}\end{array}$ & $\begin{array}{l}F_{c r}^{\prime} \\
\mathrm{kN}\end{array}$ & $\begin{array}{l}\varepsilon_{s}^{b} \\
\mu \varepsilon\end{array}$ & $\begin{array}{c}\varepsilon_{f r p}^{b} \\
\mu \varepsilon\end{array}$ \\
\hline $\mathrm{C} / \mathrm{S} 2 / \mathrm{F} 0 \mathrm{a}$ & 105 & 105 & 111 & 67 & - \\
\hline $\mathrm{C} / \mathrm{S} 2 / \mathrm{F} 0 \mathrm{~b}$ & 91 & 91 & 91 & 51 & - \\
\hline $\mathrm{C} / \mathrm{S} 2 / \mathrm{F} 0 \mathrm{c}$ & 126 & 126 & 119 & 64 & - \\
\hline $\mathrm{UL} / \mathrm{S} 2 / \mathrm{F} 1$ & 148 & 148 & 147 & 133 & 78 \\
\hline $\mathrm{UL} / \mathrm{S} 2 / \mathrm{F} 2$ & 146 & 146 & 134 & 57 & 128 \\
\hline $\mathrm{W} / \mathrm{S} 2 / \mathrm{F} 1$ & 123 & 123 & 123 & 42 & 168 \\
\hline $\mathrm{W} / \mathrm{S} 2 / \mathrm{F} 2$ & $148^{\mathrm{c}}$ & 138 & 151 & 43 & 62 \\
\hline $\mathrm{W} / \mathrm{S} 2 / \mathrm{F} 3$ & $178^{\mathrm{c}}$ & 153 & 173 & 86 & 75 \\
\hline UV/S2/F1 & 134 & 134 & 123 & 75 & 104 \\
\hline
\end{tabular}

${ }^{\mathrm{b}}$ Average strains across four gauges at failure plane for FRP and four gauges at mid stirrup height for steel. ${ }^{\mathrm{c}}$ Peak load reached after cracking

Table 4 - Design versus measured contributions to resistance

\begin{tabular}{lcccc}
\hline & $F_{S}$ & $F_{F R P}$ & \multicolumn{2}{c}{$F_{u}$} \\
\cline { 2 - 5 } Specimen & $\begin{array}{c}\text { design } \\
\mathrm{kN}\end{array}$ & $\begin{array}{c}\text { design } \\
\mathrm{kN}\end{array}$ & $\begin{array}{c}\text { design } \\
\mathrm{kN}\end{array}$ & $\begin{array}{c}\text { actual } \\
\mathrm{kN}\end{array}$ \\
\hline C/S2/F0c & 59 & - & 59 & 52 \\
$\mathrm{~W} / \mathrm{S} 2 / \mathrm{F} 1$ & 59 & 43 & 101 & 111 \\
$\mathrm{~W} / \mathrm{S} 2 / \mathrm{F} 2$ & 59 & 85 & 144 & 148 \\
$\mathrm{~W} / \mathrm{S} 2 / \mathrm{F} 3$ & 59 & 128 & 186 & 178 \\
\hline
\end{tabular}

